\title{
Immediate angioplasty: a conservative view from
}

\section{Europe}

\author{
Cost effectiveness needs to be considered
}

The main cause of acute myocardial infarction is thrombotic occlusion of a coronary artery secondary to a ruptured atheromatous plaque. The process of subsequent necrosis evolves over several hours. It is imperative to restore anterograde flow as soon as possible in order to salvage part of the ischaemic myocardium and thus to reduce morbidity and mortality. Many well designed multicentre randomised trials have conclusively shown that thrombolytic therapy limits infarct size and reduces mortality. Overall, a $27 \%$ reduction in mortality in patients treated within six hours after onset of symptoms may be expected. ${ }^{1}$ Although the in-hospital mortality exceeded $20 \%$ in the pre-thrombolytic era it has now dropped to approximately $6-8 \%$ and may become even lower with the earlier administration of and improvements in thrombolytic regimens and or pharmacological treatment. ${ }^{23}$

Thrombolytic therapy has several limitations. It does not achieve coronary patency in about $20 \%$ of patients and early complete reperfusion (TIMI 3 flow) is achieved in only half. ${ }^{4}$ Reocclusion occurs in $5-6 \%$ of the patients and some patients are left with high grade residual stenosis resulting in recurrent ischaemia which requires revascularisation in the post infarct period. ${ }^{24} \mathrm{~A}$ few patients are not eligible for thrombolytic therapy because of recent surgery, stroke, or trauma. Finally, thrombolytic therapy may cause severe or life-threatening bleeding complications (for example, haemorrhagic stroke) in about $1 \%$ of the patients. ${ }^{25}$

Direct (immediate) angioplasty is proposed as an alternative treatment to overcome the limitations of thrombolytic therapy. Three recently conducted randomised studies indicate that immediate angioplasty establishes reperfusion more rapidly and completely (TIMI 3 flow) than thrombolytic therapy, and is associated with lower mortality. ${ }^{6-9}$ Patients with suspected myocardial infarction admitted within 6-12 hours after onset of symptoms were randomised to thrombolytic therapy or immediate angioplasty. All patients received aspirin and heparin. In the three trials a total of 405 patients were randomised to angioplasty. Four to $10 \%$ of these patients did not undergo angioplasty, mainly because of three vessel or left main stem disease. This led to bypass surgery in $4-5 \%$ of these patients. ${ }^{67}$ The success rate of angioplasty, defined as TIMI 2-3 flow with a residual diameter stenosis of less than $50 \%$, was high (93-98\%). The patients randomised to thrombolytic therapy did not undergo routine coronary angiography and, therefore, their initial patency rate is not known. The combined data showed a decrease in hospital mortality $(6.4 \%$ after thrombolytics $v 2.6 \%$ after angioplasty, $\mathbf{P}=0.008$ ) as well as a decrease in early reinfarction $(7.9 \% \quad v 2.0 \%$, respectively, $P=0.001)$ and a reduction in stroke $(2.5 \% v 0.3 \%$, respectively, $\mathrm{P}=$ $0.007) .^{6-9}$ The Dutch investigators also found a $23 \%$ reduction in infarct size and better preserved left ventricular function in the angioplasty group..$^{910}$ The benefit of angioplasty in reducing infarct size and preserving ventricular function was less pronounced when patients were admitted $>2$ hours after onset of symptoms. ${ }^{10}$ The difference in survival was maintained during a mean follow up of 18 months in the study from The Netherlands. ${ }^{11}$

Notwithstanding these impressive data, several other issues need to be clarified and considered before angioplasty is advocated as the preferred treatment for all or most patients with an evolving myocardial infarct. The number of patients in these three studies is limited. The overall reduction in mortality is $60 \%$ but the $95 \%$ confidence interval ranges from $19 \%$ to $81 \%$. Thus larger additional trials are required to confirm these initial findings. Furthermore, different regimens for thrombolytic therapy were used and some of these may not have been optimal. In particular, administration of accelerated alteplase (tissue plasminogen activator) results in a superior reperfusion rate and survival than the thrombolytic regimens used in these "direct angioplasty studies". ${ }^{24}$ Future larger studies should compare immediate angioplasty with the best available thrombolytic regimen. Such studies should also determine whether the advantages of immediate angioplasty are similar in different groups of patients. Some patients may benefit more from immediate angioplasty than from thrombolytic therapy and vice versa. The benefit of immediate angioplasty is likely to be larger in the so-called "not low risk group" (patients with an anterior infarction, extensive ST segment elevation, heart failure, heart rate $>100$ beats/min, age $>70$ ) particularly when these patients can be treated within 2-3 hours after onset of symptoms and also in patients with previous bypass surgery, cardiogenic shock, or prolonged pain. ${ }^{6710}$ Similarly, the benefit and safety of thrombolytic therapy may be enhanced by adjusting thrombolytic therapy to the individual patient's characteristics and response; this could increase the number of patients for whom thrombolytic therapy is suitable. ${ }^{3}$ Although the selection criteria for various interventions need to be defined and studied in greater detail, clearly both treatments are complementary rather than competitive. ${ }^{6910}$

\section{". . . studies should also determine whether the advantages of immediate angioplasty are similar in different groups of patients"}

In all studies mentioned above, the subsequent reintervention rate was higher after thrombolytic therapy. ${ }^{6-11}$ It is, however, wrong to compare the need for repeat intervention as a clinical end point when such intervention constituted a treatment assignment in one group. Furthermore, the indications for such an intervention may be questioned in open studies conducted in centres with a low threshold for invasive procedures, particularly as a recently conducted analysis showed that residual ischaemia does not predict adverse clinical outcome even when intervention rates are low. ${ }^{12}$

Obviously, the major limitation of immediate angioplasty is its tremendous logistic burden. It requires not 
only an angioplasty facility that is always available but also a trained and experienced team of cardiologists, cardiac surgeons, cardiac anaesthesiologists, intensive care physicians, and associated paramedical personnel. Less than $10 \%$ of the hospitals in The Netherlands and other European countries have such facilities. Many patients will not have access to immediate angioplasty-some will not reach such a facility in time. Furthermore, the experience and skill of the operator are important. Can the outstanding results reported in these studies be reproduced in centres with more limited experience or are they achievable only by a highly motivated and experienced group of investigators working in an ideal environment? It should be acknowledged that although mortality was low in the angioplasty group, mortality from failed angioplasty in patients with acute myocardial infarction may exceed $30 \%$, which is much higher than the mortality from acute myocardial infarction treated with thrombolytics or conservatively. ${ }^{13}$

The benefits of reperfusion strategies, both pharmacological and mechanical, are greatest when treatment is started early. Therefore, prehospital thrombolysis may offer a more logical approach in many communities. Prehospital identification of patients with extensive evolving infarction and initiation of thrombolytic therapy has been shown not only to be feasible and safe but also to save an hour or more, with a consequent reduction in cardiac death. ${ }^{14-16}$ There is scope for a reduction in mortality of up to $42 \%$ when the interval between prehospital and inhospital thrombolysis exceeds 90 minutes. ${ }^{15}$ Another approach is to develop a strategy in which patients who would benefit particularly from immediate angioplasty are transported directly to a centre with angioplasty facilities.

Even if larger trials confirm that immediate angioplasty is better than thrombolytic therapy, the issue of costs and cost effectiveness needs to be considered. Gibbons et al showed that the direct and indirect 6 month follow up costs were significantly lower after angioplasty. ${ }^{8}$ There was, however, no significant difference in the costeffectiveness (defined by the ratio of the mean cumulative 6 month cost to the mean myocardial salvage) between the two treatment strategies. ${ }^{8}$

In conclusion, immediate angioplasty in patients with acute myocardial infarction can safely and effectively achieve reperfusion of occluded coronary arteries. One centre reported a significant reduction in infarct size after angioplasty (compared with thrombolytic therapy) particularly in those patients (about half) who were admitted within 2 hours after onset of symptoms. The combined data from the three comparative studies show a significant reduction in mortality, early reinfarction, and stroke after immediate angioplasty compared with thrombolytic therapy. Because the confidence intervals are wide these data need to be confirmed in larger studies that are underway. Thrombolytic therapy offers not only a safe and effective method of reperfusion, but also is widely available and easy to apply. Future studies should aim at refinements in thrombolytic regimen and its early prehospital administration. At present, immediate angioplasty should be considered in centres with adequate facilities and experience for those patients with extensive evolving myocardial infarction who are not eligible for thrombolytic therapy or who have an increased risk of bleeding complications.

PETER P DE JAEGERE

MAARTIN L SIMOONS

Thoraxcenter, Erasmus University Rotterdam,

The Netherlands

1 Fibrinolytic Therapy Trialists' (FTT) Collaborative Group: Indications for fibrinolytic therapy in suspected acute myocardial infarction: Collaborative overview of mortality and major morbidity results from all 3:311-22.

2 The GUSTO Investigators. An international randomized trial comparing four thrombolytic strategies for acute myocardial infarction. $N$ Engl $\mathscr{f}$ Med 1993;329:673-82.

3 Simoons ML, Arnold AER. Tailored thrombolytic therapy. A perspective. Circulation 1993;88:2556-64.

4 The GUSTO Angiographic Investigators. The effects of tissue plasminogen activator, streptokinase, or both on coronary-artery patency, ventricular function, and survival after acute myocardial infarction. $N$ Engl $f$ Med 1993;329:1615-22.

5 Simoons ML, Maggioni AP, Knatterud G, Leimberger JD, de Jaegere PPT, van Domburg $R$, et al. Individual risk assessment for intracranial haemorrhage during thrombolytic therapy. Lancet 1993;342:1523-8.

6 Grines CL, Browne KF, Marco J, Rothbaum D, Stone GW, O'Keefe J, et al. A comparison of immediate angioplasty with thrombolytic therapy for acute myocardial infarction. $N$ Engl ₹ Med 1993;328:673-9.

7 Zijlstra F, de Boer MJ, Hoorntje JCA, Reiffers S, Reiber JHC Suryapranata $\mathrm{H}$. A comparison of immediate angioplasty with intravenous streptokinase in acute myocardial infarction. N Engl f Med 1993; venous strepto 4 .

8 Gibbons RJ, Holmes DR, Reeder GS, Bailey KR, Hopfenspirger MR, Gersh BJ. Immediate angioplasty compared with the administration of a thrombolytic agent followed by conservative treatment for myocardia infarction. N Engl f Med 1993;328:685-91.

9 de Boer MJ, Hoorntje JCA, Ottervanger JP, Reiffers S, Suryapranata H, Zijlstra F. Immediate coronary angioplasty versus intravenous streptokinase in acute myocardial infarction: left ventricular ejection fraction, hospital mortality and reinfarction. F Am Coll Cardiol 1994;23:1004-8.

10 de Boer MJ, Suryapranata H, Hoorntje JCA, Reiffers S, Liem AL Miedema $\mathrm{K}$, et al. Limitation of infarct size and preservation of left ventricular function after primary coronary angioplasty compared with intravenous streptokinase in acute myocardial infarction. Circulation 1994;90:753-61.

11 de Boer MJ, Ottervanger JP, Liem AL, Hoorntje JCA, Suryapranata H, Zijlstra F. Primary coronary angioplasty versus intravenous streptokinase in acute myocardial infarction: differences in outcome during a mean follow-up of 18 months. Coronary Artery Disease (in press).

12 Volpi A, de Vita C, Franzosi MG, Gerarci E, Maggioni AP, Mauri F, et al. Determinants of 6 -month mortality in survivors of myocardial infarction Determinants of 6-month mortality in survivors of myocardial infarction
after thrombolysis. Results from the GISSI-2 data base. Circulation after thrombolysis.

13 Bedotto JB, Kahn JK, Rutherford BD, McConahay DR, Giorgi LV, Johnson WL. Failed direct coronary angioplasty for acute myocardia infarction: in-hospital outcome and predictors of death. $f \mathrm{Am} \mathrm{Coll}$ Cardiol 1993;22:690-4.

14 Feasibility, safety, and efficacy of domiciliary thrombolysis by genera practitioners: Grampian region early anistreplase trial. $\mathrm{Br} \mathrm{Med} \mathscr{f} 1992$ 305:548-53.

15 Prehospital thrombolytic therapy in patients with suspected acute myocardial infarction. The European Myocardial Infarction Project Group. $N$ Engl f Med 1993;329:383-9.

16 Bouten MJM, Simoons ML, Hartman JAM, Miltenburg AJM, van der Does E, Pool J. Prehospital thrombolysis with rt-PA in acute myocardial infarction. Eur Heart f 1992;13:925-31. 